\title{
Familial visceral myopathy: a family with at least six involved members
}

\author{
C A RODRIGUES, $N$ A SHEPHERD. J E LENNARD-JONES. P R HAWLEY. \\ AND H H THOMPSON
}

From St Mark's Hospital, London, and The London Hospital (Whitechapel), London

SUmmary A family with at least six members affected by hollow organ visceral myopathy is described. Patients in the first or second decades of life developed symptoms which included weight loss, nausea and vomiting, abdominal pain and distension, constipation and diarrhoea, and urinary symptoms. The radiological features of the disease consisted of oesophageal aperistalsis, megaduodenum, and variable dilatation of the small and large bowel. Four patients had urinary tract involvement with dilatation of the ureters and/or incomplete bladder emptying. Two patients were severely affected and needed home parenteral nutrition and surgical treatment; others were symptomatic but remained well. The characteristic pathological abnormality was vacuolar degeneration predominantly affecting the longitudinal muscle. The disease in this family appears to be transmitted by autosomal dominant mode of inheritance.

Chronic intestinal pseudo-obstruction can be caused by a wide varicty of actiological factors, but also exists in the idiopathic form, in which the primary abnormality consists of a degeneration of either the muscularis propria (visceral myopathy), or the myenteric plexus (visceral neuropathy). Sporadic and familial forms of both these diseases have been described. ${ }^{1-3}$

In this report, a family with at least six members affected by visceral myopathy is described (Fig. 1). The two most severely affected family members with histologically confirmed visceral myopathy are described in detail followed by a brief account of the other involved family members.

\section{Case reports}

FAMILY MEMBER I I I.6

This young woman first presented aged 16 years, with

Address for correspondence: Professor J F: I.ennard-Jones, Medical Research Department. Si Mark's Hospital, City Road, London F( 11 2PS.

Accepted for publication 24 January 1989. intermittent abdominal pain, abdominal distension, and vomiting. She underwent two laparotomies in the next three years, the first for small bowel volvulus. At the second laparotomy dilatation of the duodenum, ileum and the right colon was noted and an ileocolic resection carried out. Both operations were followed by prolonged ileus. Thereafter her symptoms progressed in severity and she also experienced low back pain and alternating constipation and diarrhoea, the latter having all the characteristics of steatorrhoea. At the age of 29 she was referred to St Mark's Hospital for home parenteral nutrition as she continued to lose weight despite oral antibiotics, duodenal aspiration, intermittent intravenous fluid replacement and oral nutritional supplements.

Physical examination showed evidence of wasting and abdominal distension. Faecal fat excretion was increased at $33.6 \mathrm{mmol} / \mathrm{day}$. Plain abdominal radiographs showed multiple dilated small bowel loops. A barium meal and follow through examination (Fig. 2) showed dilatation of the entire small bowel particularly marked in the duodenum. A Gastrografin (Schering Pharmaceuticals) enema showed dilatation 
II

II

IV

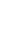

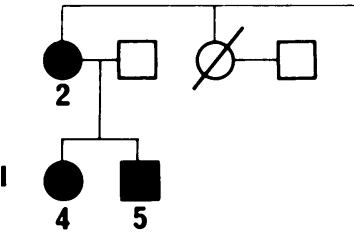

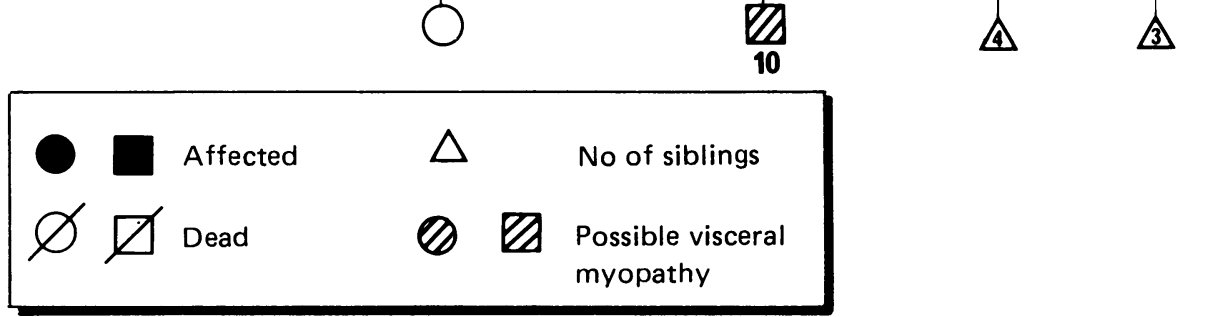

Fig. 1 Family tree: the mode of inheritance is probably autosomal dominant.

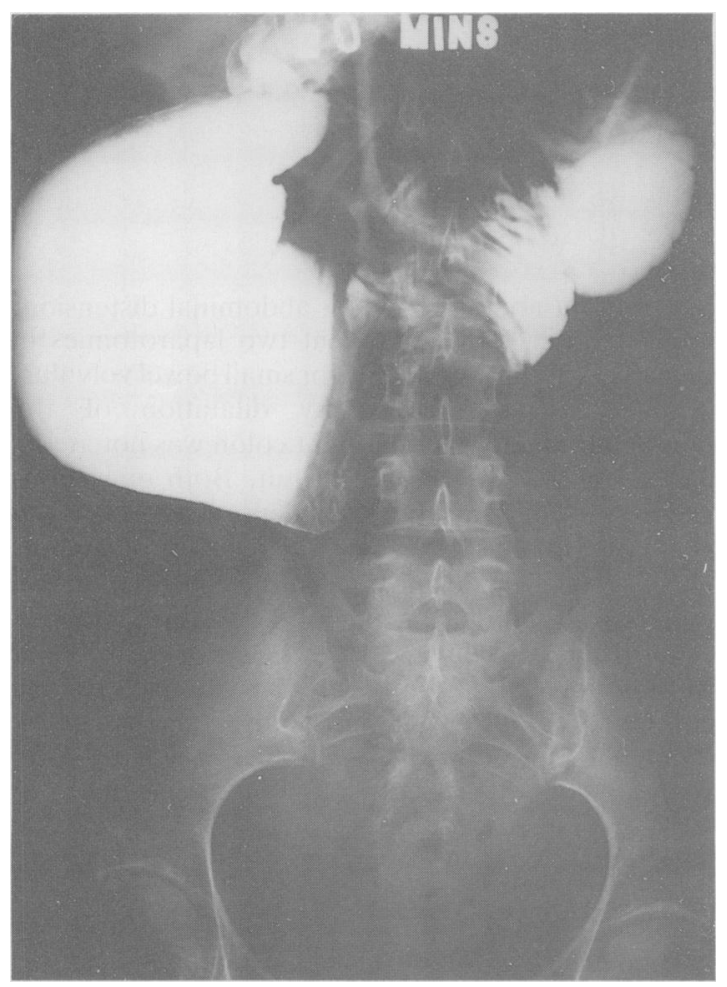

Fig.2 Barium follow through of case 111.6: Note the marked duodenal dilatation as well as less marked dilatation of the proximal jejunum. of the ascending and sigmoid colon with decreased haustration throughout. An intravenous pyelogram showed a duplex left renal pelvis and minimal dilatation of the left ureter. There was no megacystis but there was a significant post-micturition residue.

During oesophageal motility studies no peristaltic waves were recorded when liquid boluses were swallowed. Perfused tube small intestinal pressure measurements showed only two episodes of low pressure phase 3 like activity in the duodenum during a five hour fasting period. A duodenal balloon was inflated with $200 \mathrm{ml}$ air (balloon diameter of $7 \mathrm{~cm}$ ) before abdominal discomfort was felt. No motor activity was observed in response to balloon distension or ingestion of a liquid meal ( $400 \mathrm{ml}$ chicken soup).

Two months after parenteral nutrition was started she underwent elective surgery to alleviate her symptoms. At laparotomy the stomach, duodenum, and the whole of the small and large bowel were dilated. The most dilated and thin walled regions of the small bowel were resected and a Roux-en-Y gastrojejunostomy and duodenojejunostomy fashioned (Fig. 3). Postoperatively she had a persistently high output of $1-3 \mathrm{l} / \mathrm{day}$ from her nasogastric tube. As this showed no sign of abating. a gastrostomy tube was inserted six weeks later. The gastrostomy output then progressively decreased and the tube was finally removed after five months. After this operation all her symptoms improved, with particularly marked improvement in the abdominal distension but she continues to need parenteral nutrition. 


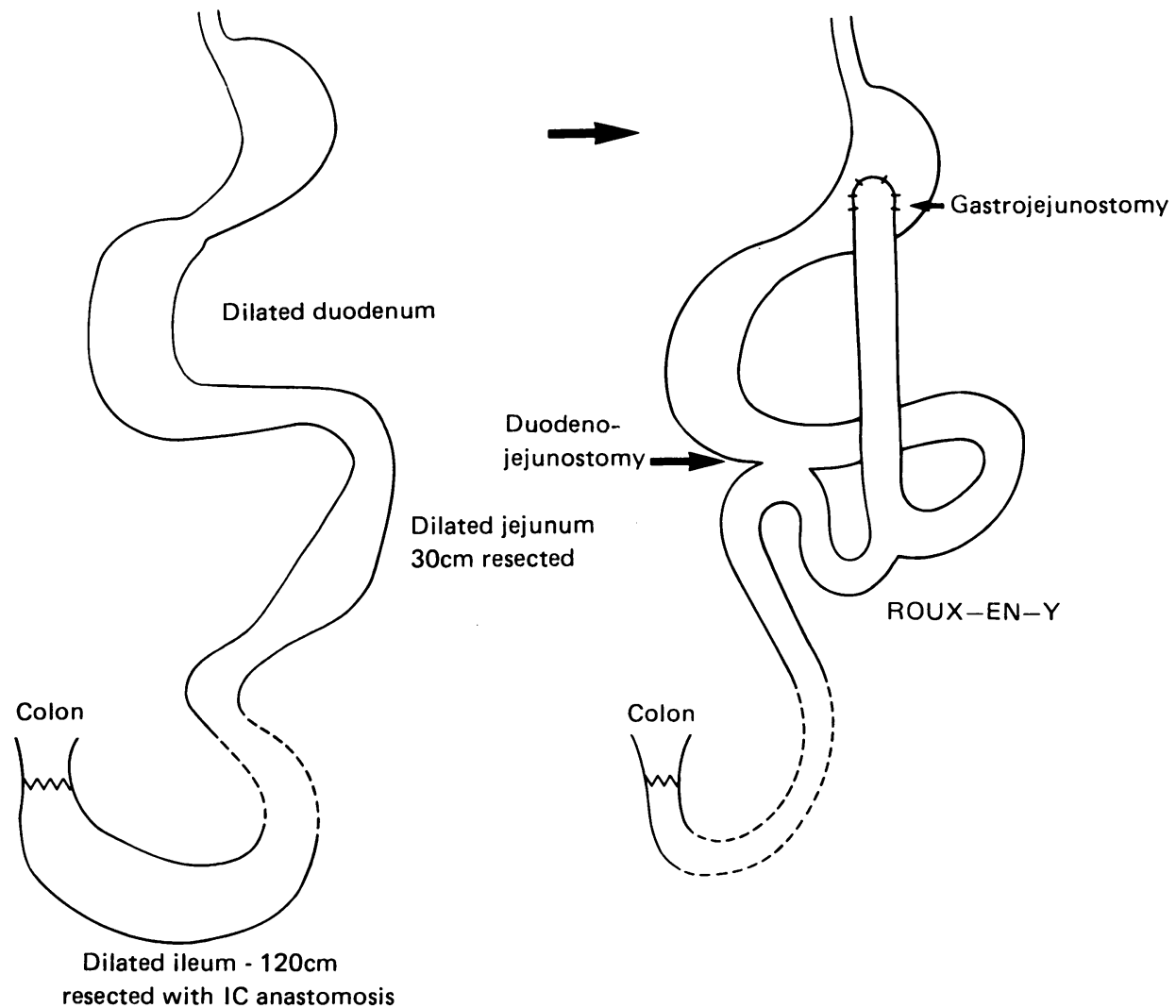

Fig. 3 Case 111.6: elective operation which was successful in improving symptoms.

FAMILY MEMBER I I I . 9

This 29 year old woman suffered from lifelong constipation which increased in severity with the onset of the menarche when it was also accompanied by abdominal pain and distension. Her symptoms were usually worse during the second half of the menstrual cycle and were often relieved by a premenstrual phase of diarrhoea. Between the ages of 18 and 20 she underwent two laparotomies for abdominal pain at one of which a histologically normal appendix was resected. A year later a barium study showed an absence of normal oesophageal peristalsis with a marked delay in emptying of contrast from the oesophagus. The duodenal loop was dilated as were the proximal small bowel loops but the distal small bowel appeared normal.

At the age of 21, during the 24th week of pregnancy, she developed absolute constipation resistant to medical treatment, and a transverse loop colostomy was fashioned. After a normal delivery the colostomy was closed but this was followed by impaction of the colon with hard faeces associated with signs of intestinal obstruction. Hence a left hemicolectomy was carried out, a transverse end-colostomy fashioned and the rectal stump oversewn. Even this procedure failed to improve intestinal transit and parenteral nutrition was commenced as her intake of food was inadequate. She was then transferred to The London Hospital (Whitechapel) for further management.

At this stage, plain abdominal films showed dilatation of both small and large bowel with many fluid levels. A technetium labelled gastric emptying study showed markedly delayed gastric emptying with a $1 / 2$ of 139 minutes (normal 37 minutes). Perfused tube pressure measurements showed three per minute antral contractile activity but no migration distally. Duodenal and jejunal fasting activity was infrequent, of low amplitude, and disorganised. Regular contractile activity (12 per minute) was present, but phasic activity was not. Most $(70 \%)$ of the activity was nonmigratory. A small meal did not abolish this abnormal fasted pattern. Radiotelemetric recordings using two pressure sensitive radiopills spaced $40 \mathrm{~cm}$ apart showed similar abnormalities to the perfused 
tube studies, but small bowel activity was found to be much more reduced.

All attempts at providing enteral nutrition failed and there was a steady deterioration in her symptoms over the next few months. Hence, the rest of the colon was resected and an end-to-side ileorectal anastomosis carried out. The ileum distal to the anastomosis was brought out as an end ileostomy to serve as an ileal 'vent' (Fig. 4). Postoperative pyrexia occurred for three weeks for which no adequate cause was found. Thereafter her symptoms improved, particularly the abdominal distension and as her intake of food increased the parenteral nutrition was stopped.

Several urinary tract infections occurred, associ-

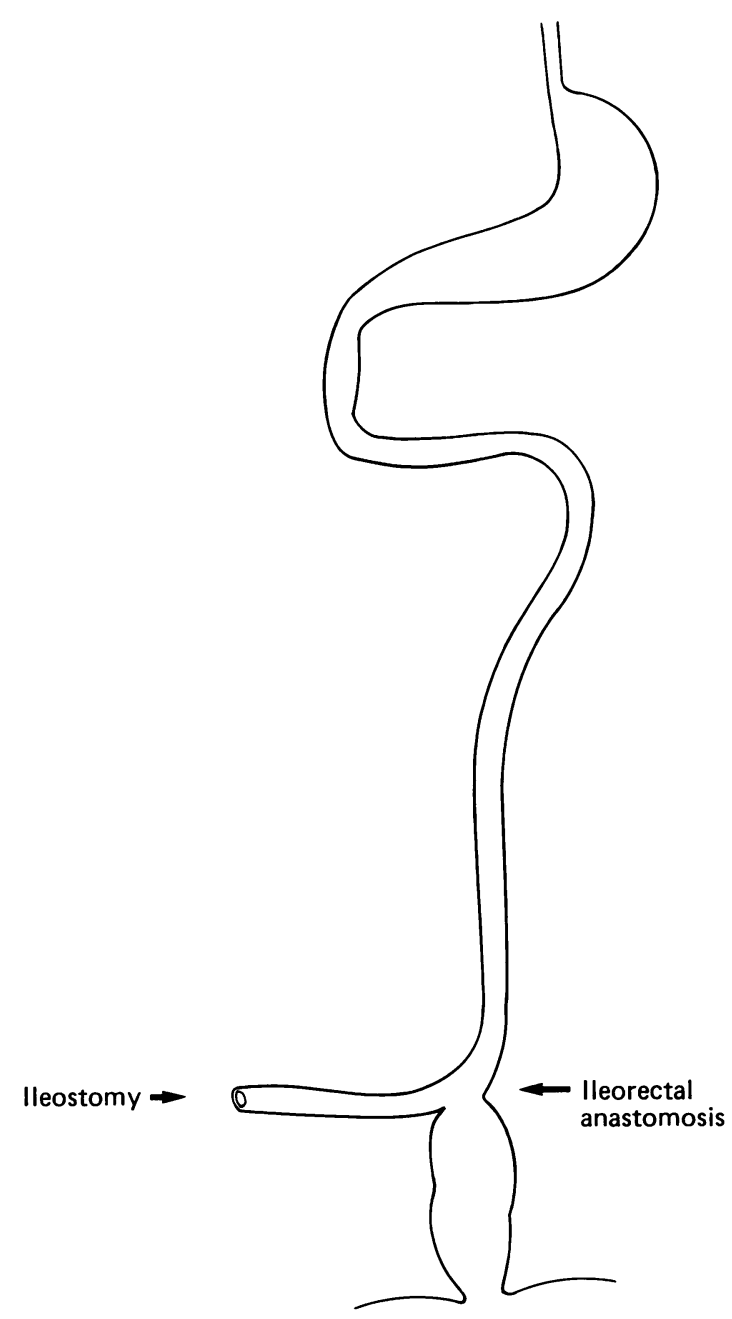

Fig. 4 Case 111.9. Operative procedure: Ileorectal anastomosis and a temporary ileal 'vent'. ated with pyrexia. An intravenous pyelogram showed incomplete evacuation of the bladder and subsequent urodynamic studies showed an atonic bladder with normal sensation.

The ileal vent was reversed about seven months after it had been constructed but after two years progression of her symptoms once more resulted in an inadequate intake of food. Vomiting was a major feature and for months regular aspiration of an indwelling nasogastric tube was needed to reduce this symptom. Parenteral nutrition was restarted at home four years ago. At present her bowels open every two to three days, and she has chronic symptoms of abdominal pain, abdominal distension and low back pain for which she takes regular analgesia. She does not work, but continues to look after her son at home.

\section{PATHOLOGY}

The small and large bowel of case no 111.6 showed marked dilatation and thinning of the wall together with fibrous thickening of the peritoneal surface. The maximum circumference of the resected specimen was $21 \mathrm{~cm}$. The small bowel and colon of case 111.9 were less markedly dilated but also showed the fibrous thickening of the peritoneal surface. The specimens were fixed, opened in $10 \%$ formol saline and routincly processed in paraffin wax. Four micron sections were stained with haematoxylin and eosin, elastic van Gieson, Gordon and Sweets' reticulin stain, Martius scarlet blue and Victoria blue.

Histological examination of the small intestine of both patients showed patchy and non-specific chronic inflammation of the mucosa with focal mild to moderate partial villous atrophy (Fig. 5). These changes were probably related to stasis and bacterial overgrowth in the dilated segments. The submucosa showed no evidence of fibrosis. In case 111.6 the muscularis propria was grossly thinned because of bowel dilatation. Although the circular muscle appeared attenuated as a result of dilatation, there was no evidence of myocyte damage and the special stains showed only a very patchy increase in collagen and elastic fibres in the circular layer. In case 111.9 the circular muscle appeared normal (Fig. 5).

The longitudinal muscle in both cases showed gross myocyte loss with vacuolar degeneration (Fig. 6). Special stains showed an excess of collagen and elastic fibres in the external muscle coat, and this fibrosis and elastosis extended into serosal tissues. The submucosal and myenteric nerve plexuses appeared normal throughout and there was no histological abnormality of blood vessels in either case.

The histopathological features, in particular the selective damage to the longitudinal muscle with 


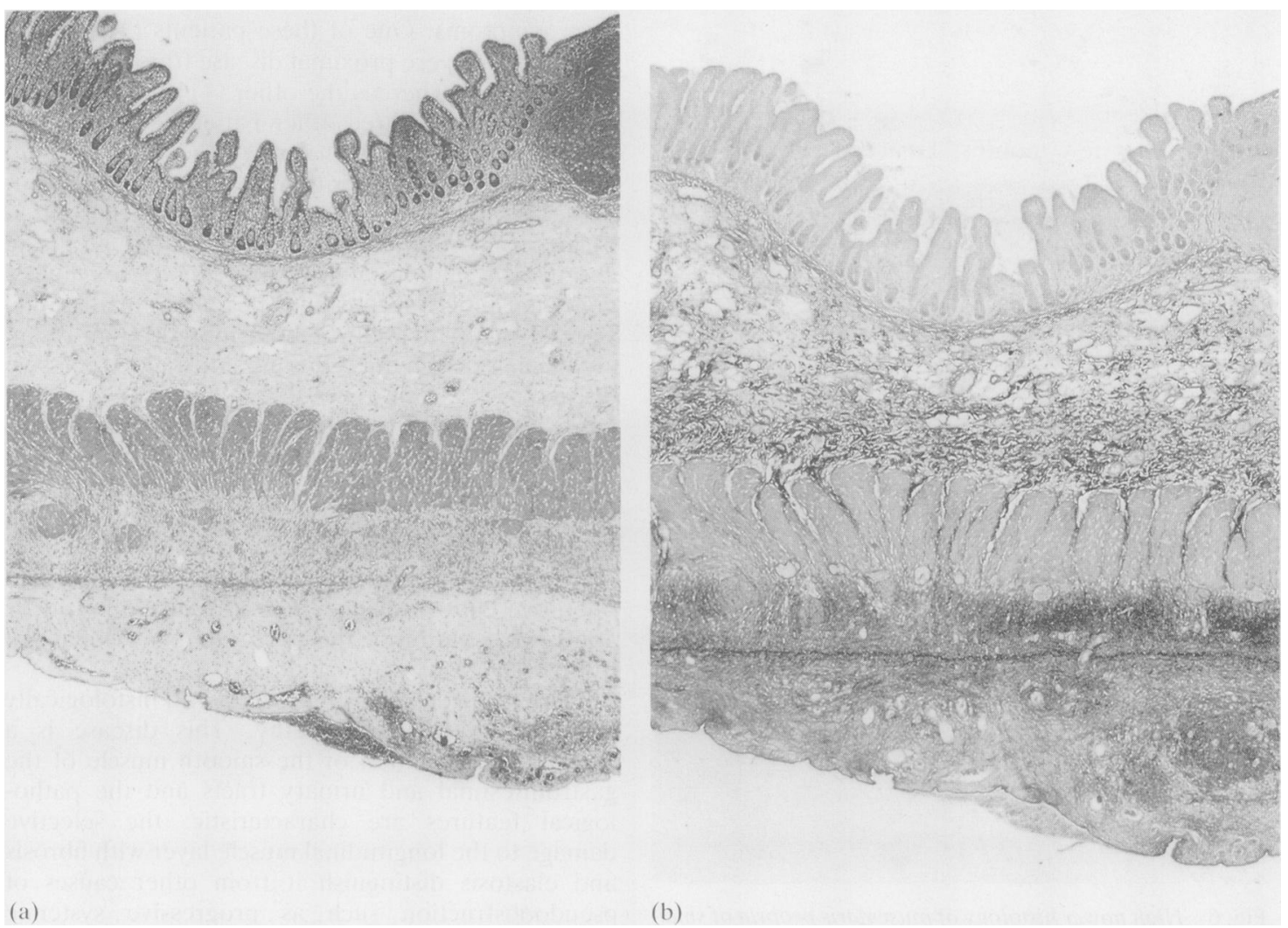

Fig. 5 (a) Cross section of the small intestine of case 111.9. There is mild partial villous atrophy and chronic inflammation of the mucosa. the most striking changes are in the longitudinal muscle which is degenerate. $H$ and $E \times 25$. (b) The longitudinal muscle shows fibrosis and elastosis. The serosal tissues also show fibrosis. Elastic van Gieson $\times 25$.

fibrosis, elastosis and vacuolar degeneration, are characteristic of hollow visceral myopathy. ${ }^{5}$ th There was no histological evidence of progressive systemic sclerosis or neuropathological abnormality.

OTHER FAMII.Y MEMBERS (Fig. 1, Table)

Four other family members (nos 11.2, 111.4, 111.5, and 111.7) have radiological manifestations of pseudoobstruction (Fig. 7). These patients have mild symptoms and are able to eat a normal diet. They have not needed any special nutritional treatment. In addition four family members (nos 1.1, 11.3, 111.8 and IV.10) have a history of gastrointestinal symptoms but no investigations have been carried out to date.

\section{Discussion}

The clinical, radiological and pathological features in this family concur with previous descriptions of familial visceral myopathy. ${ }^{+12}$ Apart from the typical symptoms of abdominal pain and distension, constipation and/or diarrhoea, three patients $(111.5,111.6$, 111.9) also complained of constant low back pain. There was no obvious musculoskeletal cause for this symptom, and it may well be a consequence of the underlying disease process.

Two patients $(111.4,111.9)$, experienced an exacerbation of their symptoms during the second half of the menstrual cycle. In one of these patients (111.9) this cyclical variation was marked, and her constipation/pseudoobstruction became very severe in late pregnancy. This phenomenon may be related to changes in female sex hormone or prostaglandin levels that occur during the course of the menstrual cycle and in pregnancy.

This family illustrates the variable clinical expression of this disease: two patients with severe gastrointestinal involvement needed home parenteral nutrition and also underwent surgery to alleviate 




Fig. 6 High power histology of muscularis propria of small intestine of patient 111.9. The circular muscle (above) appears relatively normal while the longitudinal muscle shows gross vacuolar degeneration. Many of the vacuoles contain fragments of degenerate muscle cells. $H$ and $E \times 400$. their symptoms. One of these patients (111.6) had particularly severe proximal disease (duodenum and small bowel), whereas the other (111.9) had severe colonic disease. Three other patients $(11.2,111.4$, 111.5) had a more benign form of the illness and did not need any special nutritional or surgical treatment .

In this kindred the disease is probably transmitted by autosomal dominant inheritance although in the absence of male-to-male transmission, sex linked dominant inheritance cannot be ruled out. Familial visceral myopathy can be transmitted either as an autosomal dominant ${ }^{+7}$ or an autosomal recessive disease. ${ }^{\text {-12 }}$

Elective surgery can alleviate chronic symptoms in patients with severe visceral myopathy. members of this family $(111.6,111.9)$ improved after surgical treatment. Postoperative morbidity may be increased, however, as a result of postoperative ileus or sepsis. Some authors ${ }^{1+}$ recommend routine preoperative culture of duodenal aspirate followed by appropriate antibiotic therapy if there is evidence of bacterial overgrowth.

This report describes a kindred with histologically confirmed visceral myopathy. This disease is a primary degeneration of the smooth muscle of the gastrointestinal and urinary tracts and the pathological features are characteristic: the selective damage to the longitudinal muscle layer with fibrosis and elastosis distinguish it from other causes of pseudoobstruction such as progressive systemic sclerosis. ${ }^{16}{ }^{17}$ Increasing numbers of such patients are now being reported probably because of an increased awareness of the chronic intestinal pseudoobstruction syndromes, as well as improved survival of the most

Table Clinical details and histology in affected family members

\begin{tabular}{|c|c|c|c|c|c|}
\hline $\begin{array}{l}\text { Case } \\
\text { no }\end{array}$ & $\begin{array}{l}\text { Age } \\
(y r)\end{array}$ & Sex & Clinical details & Nutrition & Histology \\
\hline 1.1 & D & M & History of "bowel symptoms." & \multicolumn{2}{|c|}{ No details available } \\
\hline 11.2 & 58 & $\mathrm{~F}$ & Megaduodenum. Jejunal dilatation. & Normal & - \\
\hline 11.3 & D & $\mathrm{F}$ & Lifelong constipation and abdominal distension. & Normal & - \\
\hline 114.4 & 27 & $\mathrm{~F}$ & $\begin{array}{l}\text { Megaduodenum. Ileal dilatation. Loss of colonic haustral pattern. } \\
\text { Ultrasound: Large capacity bladder, emptying complete. }\end{array}$ & Normal & - \\
\hline 111.5 & 24 & M & Megaduodenum. & Normal & - \\
\hline 111.6 & 32 & $\mathrm{~F}$ & $\begin{array}{l}\text { Severe Megaduodenum. Decreased oesophageal motility. Small } \\
\text { bowel, colonic involvement. Urinary tract involvement. }\end{array}$ & HPN & $\begin{array}{l}\text { Visceral } \\
\text { myopathy }\end{array}$ \\
\hline 111.7 & 37 & M & $\begin{array}{l}\text { Megacolon. Bilateral hydronephrosis and hydroureter (said to be } \\
\text { due to urethral stricture) }\end{array}$ & \multicolumn{2}{|c|}{ Lost to follow-up } \\
\hline 111.8 & 44 & $\mathrm{~F}$ & "Bowel complaints". Normal barium enema. & Normal & - \\
\hline 111.9 & 29 & $\mathrm{~F}$ & $\begin{array}{l}\text { Oesophageal aperistalsis. Delayed gastric emptying. } \\
\text { Megaduodenum and proximal small bowel involvement. Severe } \\
\text { colonic involvement. Atonic bladder. }\end{array}$ & HPN & $\begin{array}{l}\text { Visceral } \\
\text { mỵopithy }\end{array}$ \\
\hline IV.10 & 6 & M & Constipation. & Normal & \\
\hline
\end{tabular}

D: Deceased; HPN: home parenteral nutrition. 


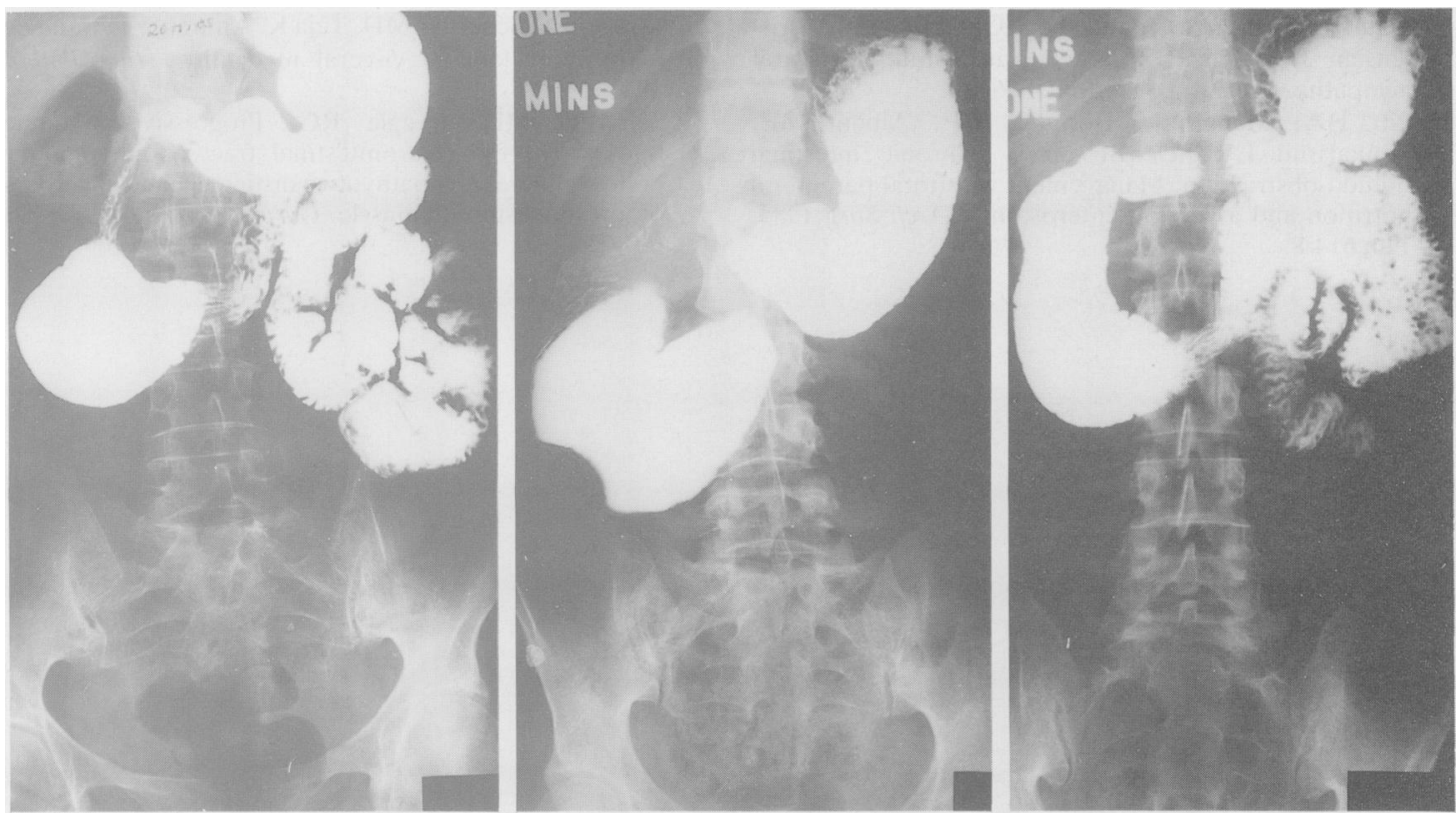

Fï. 7 Barium follow through examinations of three other family members: From left to right-case 11.2, case 111.4, and case /11.5. All three patients have' a megaduodenum.

severely affected cases with the advent of home parenteral nutrition.

Presented at the British Society of Gastroenterology Jubilec Meeting, London, September 1987 and published as an abstract. Dr G P N Kendall and Dr R Valori carried out motility studies on two of the patients described in this paper. The authors are grateful to them for allowing us to use these data. D) ( A Rodrigues received a grant from North East Thames Regional Health Authority.

\section{References}

1 Schuffler MI). (hronic intestinal pseudo-obstruction syndromes. Med ( $\operatorname{lin} N$ dm 1981: 65: 1331-.58.

2 Fatulk MI). Anuras S. Christensen J. Chronic intestinal psecudo-obstruction. (iastroenterology 1978: 74: 922-31.

3 Isaacs P. Keshavarzian A. Intestinal pseudo-obstruction - a review. Postgrad Med J 1985: 61: 1033-8.

4 Faulk D)., Anuras S. Giardner D. Mitros FA. Summers RW, (hristensen J. A familial visceral myopathy. Ann Intern Med 1978: 89: 600)-6.

5 Schuffler MI). Lowe MC. Bill AH. Studies of idiopathic intestinal pseudo-obstruction. 1. Hereditary hollow visceral myopathy: clinical and pathological studies. (iastrocherology 1977: 73: 327-38.

6 Schuffler MI). Pope (E. Studies of idiopathic intestinal pscudo-obstruction. 2. Hereditary hollow visceral myopathy: family studies. Gastroenterology 1977; 73: 339-44.

7 Shaw A. Shaffer H. Tcja K, Kelly T, Grogan E, Brum C. A perspective for pacdiatric surgeons: Chronic idiopathic intestinal pseudo-obstruction. J Pediatr Surg 1979: 14: 719-27.

8 Anuras S, Mitros FA, Nowak TV, Ionasescu VV, Gurll NJ, Christensen J, Green J. A familial visceral myopathy with external ophthalmoplegia and autosomal recessive transmission. Gastroenterology 1983; 84: 346-53.

9 Ionasescu VV, Thompson HS, Aschenbrener C, Anuras S. Rick WS. Late-onset oculogastrointestinal muscular dystrophy. Am J Med Genet 1984; 18: 781-8.

10 Jacobs E. Ardichvili D. Perissino A. Gottignies P, Hanssens J-F. A case of familial visceral myopathy with atrophy and fibrosis of the longitudinal muscle layer of the entire small bowel. Gastroenterology 1979; 77: 74.5-50).

11 Anuras S, Mitros SA, Milano A, Kuminsky R, Decanio R, Green JB. A familial visceral myopathy with dilatation of the entire gastrointestinal tract. Gastroenterology 1986; 90: 385-90.

12 Alstead EM. Murphy MN, Flanagan AM, Bishop AE, Hodgson HJF. Familial autonomic visceral myopathy with degeneration of muscularis mucosac. J Clin Pathol 1988: 41: 424-9.

1.3 Schuffler MD. Deitch EA. Chronic idiopathic intestinal pscudo-obstruction. A surgical approach. Ann Surg 1980: 192: 752-61. 
14 Anuras S, Shirazi S, Faulk DL, Gardner GD, Christensen J. Surgical treatment in familial visceral myopathy. Ann Surg 1979; 189: 306-10.

15 Pitt HA, Mann LL, Berquist WE. Ament ME, Fonkalsrud EW, DenBesten L. Chronic intestinal pscudo-obstruction. Management with total parenteral nutrition and a venting enterostomy. Arch Surg 1985; $120 ; 614-8$.
16 Mitros FA, Schuffler MD. Teja K. Anuras S. Pathologic features of familial visceral myopathy. Hum Pathol 1982: 13: 825-33.

17 Schuffler MD, Becgle R(i. Progressive systemic sclerosis of the gastrointestinal tract and hereditary hollow visceral myopathy: two distinguishable disorders of intestinal smooth muscle. (jastroenterology 1979): 77: 664-71. 